Cahiers $d u$ MONDE RUSSE

\section{Cahiers du monde russe}

Russie - Empire russe - Union soviétique et États indépendants

48/2-3 | 2007

Les résonances de 1905

\title{
La pétition des musulmans du Caucase en réponse à l'Oukase du 18 février 1905
}

Édith Ybert-Chabrier

\section{OpenEdition}

\section{Journals}

Édition électronique

URL : https://journals.openedition.org/monderusse/8999

DOI : 10.4000/monderusse.8999

ISSN : $1777-5388$

Éditeur

Éditions de l'EHESS

\section{Édition imprimée}

Date de publication : 15 avril 2007

Pagination : 243-258

ISBN : 978-2-7132-2147-7

ISSN : $1252-6576$

Référence électronique

Édith Ybert-Chabrier, "La pétition des musulmans du Caucase en réponse à l'Oukase du 18 février 1905 », Cahiers du monde russe [En ligne], 48/2-3 | 2007, mis en ligne le 01 janvier 2007, consulté le 04 septembre 2022. URL : http://journals.openedition.org/monderusse/8999 ; DOI : https://doi.org/ 10.4000/monderusse.8999 
chercher : repérer : avancer

Cet article est disponible en ligne à l'adresse :

http://www.cairn.info/article.php?ID REVUE=CMR\&ID NUMPUBLIE=CMR 482\&ID ARTICLE=CMR 4820243

\title{
La pétition des musulmans du Caucase en réponse à l'Oukase du 18 février 1905
}

par Édith YBERT-CHABRIER

\section{Editions de l'EHESS | Cahiers du monde russe}

\author{
$2007 / 2-3-$ Vol 48 \\ ISSN 1252-6576 | ISBN 9782713221477 | pages 243 à 258
}

Pour citer cet article :

- Ybert-Chabrier n, La pétition des musulmans du Caucase en réponse à l'Oukase du 18 février 1905, Cahiers du monde russe $2007 / 2-3$, Vol 48, p. 243-258.

Distribution électronique Cairn pour les Editions de l'EHESS.

(C) Editions de l'EHESS. Tous droits réservés pour tous pays.

La reproduction ou représentation de cet article, notamment par photocopie, n'est autorisée que dans les limites des conditions générales d'utilisation du site ou, le cas échéant, des conditions générales de la licence souscrite par votre établissement. Toute autre reproduction ou représentation, en tout ou partie, sous quelque forme et de quelque manière que ce soit, est interdite sauf accord préalable et écrit de l'éditeur, en dehors des cas prévus par la législation en vigueur en France. Il est précisé que son stockage dans une base de données est également interdit. 


\section{LA PÉTITION DES MUSULMANS DU CAUCASE EN RÉPONSE À L'OUKASE DU 18 FÉVRIER 1905}

Pétitions, requêtes, motions, adresses de tous genres sont rédigées lors des nombreuses réunions qui se tiennent dans la Russie des années 1904-1907 et expédiées aux autorités locales ou aux différents ministères, voire au Comité des ministres. Mais la campagne de pétitions, suscitée par l'oukase de Nicolas II du 18 février 1905 et close par l'oukase impérial du 6 août, a un statut officiel particulier. En effet, ces décrets sont publiés, pour le premier, le même jour que le rescrit à Bulygin annonçant l'appel à des élus du peuple pour participer à l'élaboration et à la discussion des projets législatifs, pour le second, simultanément avec le manifeste annonçant la convocation d'une assemblée, dite douma de Bulygin. Cette campagne a donc lieu après les premières concessions importantes de Nicolas II, qui s'engage ainsi dans la voie de réformes, et elle s'achève lors de l'annonce de la création d'une Douma d'État, aux pouvoirs tellement restreints qu'elle soulève un tollé de protestations de toute l'opposition. Les pétitions ont fait l'objet d'une recherche systématique menée par l'historien de Leningrad Rafail Šolomovič Ganelin, qui a dépouillé les archives du Conseil des ministres et leur a consacré plusieurs articles ${ }^{1}$ qui brossent un tableau précis, quoique quelque peu formel. Or le suivi de cette campagne à travers la revue Pravo, hebdomadaire juridique publié à Saint-Pétersbourg, montre l'intérêt qu'il y aurait à analyser le contenu de ces pétitions. Dans le cas du Caucase, la campagne permet de comparer les pétitions émanant de diverses entités régionales ou nationales. En quoi leurs analyses et revendications convergent-elles ? Sur quels points divergent-elles ? Nous nous focaliserons sur les pétitions des musulmans du Caucase et tenterons, par la mise en perspective de leur contenu en fonction de la situation régionale, de dégager les

1. Rafail Š. Ganelin, « Peticii po ukazu 18 fevralja 1905g. » [Pétitions en réponse à l’oukase du 18 février 1905], Vspomogatel'nye istoričeskie discipliny, XX, 1989, p. 150-163 ; XXI, 1990, p. 119-136. 
perceptions de cette communauté et les lignes de force utiles à la compréhension d'évolutions ultérieures dans la région.

\section{La campagne de pétitions (18 février-6 août 1905)}

La grande nouveauté de l'oukase du 18 février est, selon les termes mêmes de l'empereur, « de donner à tous nos fidèles sujets, préoccupés du bien public et des besoins de l'État, la possibilité d'être entendus par Nous ». Pour cela, il est ordonné au Conseil des ministres de procéder à « l'examen et à la discussion des avis et propositions qui Nous sont adressés par les particuliers et par les corps constitués et qui concernent le perfectionnement de l'organisation de l'État (gosudarstvennoe blagoustrojstvo) et l'amélioration du bien-être du peuple $»^{2}$.

En fait, au cours de la campagne des banquets qui suivit la réunion des zemstva de novembre 1904, soit bien avant cette légalisation des « avis et propositions », les libéraux avaient adopté et diffusé de nombreux programmes et résolutions réclamant de profonds changements politiques et sociaux. La revue Pravo avait d'ailleurs, avant même la parution de l'oukase de février, publié une rubrique régulière consacrée aux « adresses, déclarations, résolutions des zemstva ou des assemblées de la noblesse, etc. ». Et c'est bien la présentation au tsar d'une pétition politique des ouvriers de Saint-Pétersbourg qui est à l'origine du Dimanche rouge.

Après l'oukase du 18 février, les pétitions arrivent en très grand nombre au Conseil des ministres, au sein duquel a été créé un service chargé de les examiner. Ganelin en a dénombré 618, qui émanent de toutes les régions de l'Empire (hormis des provinces baltes, qui ont participé si massivement à cette campagne - près de 400 pétitions à elles seules ${ }^{3}-$, qu'il les comptabilise à part).

Sur ces 618 pétitions :

- 127 expriment leur solidarité avec l'une des pétitions du royaume de Pologne ;

- 161 émanent du monde paysan ;

-3 des ouvriers ;

- 30 de zemstva de gouvernement ;

- 49 de zemstva de districts ;

- 109 de doumas urbaines.

Parmi les revendications qui reviennent le plus souvent, citons (dans les termes employés par Ganelin) :

- la réunion de représentants, dans 231 pétitions ;

- l'abolition des ordres (soslovie), de leurs privilèges et des limitations nationales, dans 163 pétitions ;

- l'octroi des libertés civiques, dans 153 pétitions ;

2. «Imennoj vysočajšij ukaz dannyj Pravitel'stvujuščemu Senatu. 1905 goda, Fevralja 18ogo » [Oukase impérial au Sénat, 18 février 1905], Pravo, n 7, 20 février 1905, col. 475.

3. R. Š. Ganelin, «Peticii estonskih, latvijskih i litovskih krest’jan po ukazu 18 fevralja 1905g. » [Pétitions des paysans estoniens, lettons et lituaniens en réponse à l'oukase du 18 février 1905], Vspomogatel'nye istoričeskie discipliny, XVIII, 1987, p. 195-208. 
- les élections des représentants et de l'Assemblée constituante au suffrage universel, direct, égal et secret (le fameux « quatrain»), dans 129 pétitions ${ }^{4}$.

Quel a été l'impact de ces pétitions sur la politique gouvernementale ? Il est difficile de le préciser. Plusieurs rapports ont été présentés à Nicolas II sur leur contenu. Celui-ci l'a-t-il influencé d'une manière ou d'une autre, au milieu des tergiversations qui l'amenèrent à l'adoption du Manifeste du 17 octobre ? Il n'est pas possible de l'affirmer.

En revanche, leur élaboration a fait participer pour la première fois à des débats politiques bien des citoyens qui se sont ainsi familiarisés avec des notions nouvelles, sur les différents modes de scrutin ou types d'impôts par exemple. C'est ce que précisait Witte dans un mémorandum au tsar du 9 octobre où il faisait remarquer que l'année 1905 avait entraîné une révolution dans les esprits, qu'elle avait fait avancer la Russie de nombreuses années en popularisant des idées telles que le suffrage universel ou la nationalisation du sol. François-Xavier Coquin, qui s'est intéressé aux motions paysannes, souligne aussi le rôle éducatif de ces motions qui rapprochaient la campagne des villes ${ }^{5}$.

\section{Les pétitions au Caucase}

Au Caucase, la révolution a pris un tour bien particulier, tant par son ampleur et un calendrier propre des grèves et des mouvements agraires, particulièrement en Gourie, que du fait des violences interethniques.

Comme dans le reste de la Russie - à la différence qu'il n'y avait pas de zemstva au Caucase, qui y sont donc absents de la scène politique - , différents corps constitués, doumas urbaines, associations professionnelles ou représentants des diverses régions et nationalités ont soumis des pétitions au Conseil des ministres.

Là aussi, les premières motions sont envoyées aux autorités centrales avant l'oukase du 18 février.

En voici un rappel, dans l'ordre chronologique de leur publication en 1905 dans la revue Pravo:

- la première est un mémoire (pamjatnaja zapiska) des Géorgiens au président du Conseil des ministres ${ }^{6}$;

- la seconde, est une résolution adoptée la veille du manifeste impérial sur les pétitions, le 17 février, par la Société de bourse de Bakou ${ }^{7}$, dénonçant la désorganisation

4. Ganelin, « Peticii po ukazu 18 fevralja 1905g. », p. 132-136.

5. François-Xavier Coquin, «Un aspect méconnu de la Révolution de 1905 : les 'motions paysannes' », in Fr.-X. Coquin, Céline Gervais-Francelle, éds., 1905, la première révolution russe, P. : Publications de la Sorbonne - Institut d'études slaves, 1986, p. 194.

6. «Pamjatnaja zapiska gruzin predsedatelju komiteta ministrov» [Mémorandum des Géorgiens au président du Comité des ministres], Pravo, n 7, 20 février 1905, col. 499-501.

7. «Rezoljucija črezvyčajnago obščago sobranija Bakinskago birževogo obščestva ot 17 fevralja 1905g. » [Résolution de l'assemblée générale extraordinaire de la société de Bourse de Bakou du 17 février 1905], Pravo, n 11, 20 mars 1905, col. 832-833. 
depuis trois mois, à cause des grèves, de l'industrie pétrolière et de l'ensemble des industries et commerces, et la situation de désolation et de panique créée par les massacres qui ont ensanglanté Bakou du 6 au 10 février et provoqué l'arrêt presque complet de l'activité économique. Elle demande l'instauration d'une commission d'enquête judiciaire sur ces massacres, à laquelle devraient participer des représentants de la société et de la presse. La résolution passe ensuite à des revendications plus générales qui sont à l'unisson de celles des libéraux et d'autres représentants des milieux industriels et financiers des régions centrales de la Russie ;

- la troisième est une adresse (vsepoddannejšij adres) des nobles du gouvernement de Tiflis ${ }^{8}$;

- la quatrième est une pétition de l'administration urbaine d'Erevan sur le perfectionnement du gouvernement, qui émane des deux communautés peuplant le gouvernement d'Erevan, les Arméniens et les musulmans ${ }^{9}$;

- la cinquième est la pétition des musulmans du Caucase au Comité des ministres ${ }^{10}$;

- la sixième est une pétition des Arméniens ${ }^{11}$, émanant de représentants de la population arménienne à des réunions organisées à Tiflis ;

- la septième est une note sur les besoins locaux rédigée au nom de la douma de Tiflis ${ }^{12}$ par le maire de cette ville, Vermišev ${ }^{13}$, un libéral arménien ;

- la dernière est une note sur l'organisation et le gouvernement de la Géorgie émanant de la douma urbaine de Kutajsi et s'appuyant sur les revendications des paysans et des nobles de Géorgie ${ }^{14}$.

Ces huit pétitions sont parues dans la revue Pravo, qui en publie le texte intégral avec un préambule, souvent long, présentant la situation locale et les principes qui inspirent les revendications proprement dites. Seule la pétition des Arméniens est

8. «Vsepoddannejšij adres dvorjan Tiflisskoj gubernii » [Très respectueuse adresse des nobles du gouvernement de Tiflis], Pravo, n 15, 15 avril 1905, col. 1192.

9. «Peticija Erivanskago gorodskogo upravlenija ob usoveršenstvovanii gosudarstvennago porjadka » [Pétition de l'administration urbaine d'Erevan relative au perfectionnement du gouvernement], Pravo, ${ }^{\circ} 17,1^{\mathrm{er}}$ mai 1905, col. 1405-1407.

10. «Peticija kavkazskih musul'man v komitet ministrov» [Pétition des musulmans du Caucase au Comité des ministres], Pravo, n 18, 8 mai 1905, col. 1489-1496. Ci-après : Pétition.

11. «Peticija Armjan » [Pétition des Arméniens], Pravo, n 19, 14 mai 1905, col. 1600-1601.

12. «Zapiska o mestnyh nuždah, sostavlennaja tiflisskim gorodskim golovoj, po poručeniju komissi po sostavleniju zapiski o vidah i predpoloženijah tiflisskoj gorodskoj dumy otnositel'no usoveršenstvovanija gosudarstvennago blagoustrojstva i upročenija narodnago blagosostojanija » [Note sur les besoins locaux rédigée par le maire de la ville de Tiflis de la part de la commission pour la rédaction d'une note sur les vues et propositions de la douma urbaine de Tiflis au sujet du perfectionnement de l'organisation de l'État et de l'amélioration du bien-être du peuple], Pravo, n $^{\circ} 22,8$ juin 1905, col. 1797-1805.

13. Il s'agit de Hristofor Avvakumovič Vermišev, né en 1863 à Tiflis, fils d'un industriel du pétrole à Bakou, éditeur de plusieurs journaux de Bakou et Batoumi (R.G. Suny, The Making of the Georgian Nation, Bloomington: Indiana University Press, 1994, p. 168 ; site généalogique : http://www.vgd/ru/V/).

14. «Zapiska ob ustrojstve upravlenija Gruzej » [Note sur l'organisation du gouvernement de la Géorgie], $\operatorname{Pravo}^{\circ}$ 27, 10 juillet 1905, col. 2230-2239. 
présentée sans préambule et s'en tient à ses résolutions finales. D'autres pétitions ont été envoyées au Conseil des ministres, d'autres requêtes ou pétitions adressées soit à Bulygin, soit au vice-roi du Caucase, ou encore à des responsables locaux ${ }^{15}$. Elles seraient à prendre en compte dans des études régionales ou sectorielles.

Il faut avoir à l'esprit que ces pétitions émanent des milieux réformateurs et non de groupes révolutionnaires qui appellent à renverser l'autocratie. Selon leur propre terminologie, ces réformateurs sont engagés dans le mouvement de libération, non dans une révolution. Mais ils font état des troubles agraires et des grèves, que seules des réformes peuvent faire cesser, et présentent des revendications radicales, parfois incompatibles avec le maintien de l'autocratie.

Malgré l'hétérogénéité des acteurs, des caractéristiques communes se dégagent. Il faut cependant mettre à part la pétition de la société de bourse de Bakou déjà évoquée et celle des nobles de Tiflis, très courte et qui diffère des autres par un ton plus conciliant. Les six autres pétitions :

- s'expriment au nom des différentes couches de la société et comportent, à côté des revendications générales, des revendications paysannes et ouvrières ;

- dressent un bilan très sévère du gouvernement et de l'administration russes, particulièrement durant les vingt dernières années ;

- s'expriment sur les réformes à entreprendre au niveau panrusse, réformes d'inspiration libérale.

Elles réclament :

- l'égalité des habitants du Caucase avec ceux des régions centrales de la Russie ;

- le respect des langues et particularités nationales, mais n'expriment pas d'aspiration à l'indépendance ;

- la participation aux nouvelles institutions, sans distinction de confession religieuse et de nationalité.

Les revendications communes à ces six pétitions portent sur :

- l'éducation, et particulièrement sur l'emploi de la langue nationale dans l'enseignement ;

- la mise à la disposition des paysans sans terre ou ayant trop peu de terre des domaines de l'État encore libres ;

- l'amélioration de la condition ouvrière ;

- l'organisation judiciaire;

- l'introduction des zemstva au Caucase ;

- la réforme de l'autonomie des villes dans les sens d'une complète libération de l'ingérence des pouvoirs administratifs ;

15. Les habitants des diverses régions ou villes du territoire de l'actuel Azerbaïdjan : gouvernement d'Elizavetpol', district de Zakatala, Sal'jan et district de Dževad, ville de Nuhi, prennent part à la campagne de pétitions (D.B. Seidzade, Iz istorii azerbajdžanskoj buržuazii V načale XX veka [Histoire de la bourgeoisie azerbaïdjanaise au début du XXe siècle], Bakou : Elm, 1978, p. 63). Les professeurs musulmans des écoles de Bakou y participent aussi (Ahmed Ahmedov, Azerbajdžanskie tjurki v revoljucii 1905 goda [Les Turcs azerbaïdjanais dans la révolution de 1905], Bakou : Azerbajdzan milli ensiklopedijasy, 2002, p. 156-157). 
- le respect de la loi par l'administration, l'inviolabilité de la personne et de son domicile, la liberté de conscience, de parole, la liberté de la presse (tant en russe que dans les langues vernaculaires), les libertés de réunion et d'association.

La pétition des musulmans du Caucase se distingue de l'ensemble des autres car elle met au premier plan l'abolition des discriminations qui frappent les musulmans et demande d'abord des mesures de rattrapage, de mise à niveau en leur faveur. Elle s'exprime sur les réformes à entreprendre au Caucase, mais ne se prononce pas sur les nouvelles institutions à mettre en place au niveau panrusse, se contentant de demander l'alignement du Caucase sur les régions centrales et la participation des musulmans aux institutions sur un pied d'égalité. Elle ne prend position au niveau panrusse que pour réclamer l'instauration des libertés fondamentales.

\section{La pétition des musulmans du Caucase}

Cette pétition est un texte fondateur pour l'histoire des musulmans du Caucase, et pour l'histoire de la Russie en général. Une historienne azerbaïdjanaise, très respectueuse des canons idéologiques de l'historiographie soviétique, D.B. Seidzade, en reconnaît l'importance et décrit avec précision les démarches, pétitions et articles de la presse locale de l'époque ${ }^{16}$. Elle en donne toutefois une image parfois caricaturale, dénonçant à maintes reprises la prétention de la bourgeoisie locale de s'ériger en défenseur de «la nation » et l'accusant de servir ses seuls intérêts en les faisant passer pour ceux du peuple tout entier (obščenarodnye ou obščenacional'nye) ${ }^{17}$. À l'inverse, Ahmed Ahmedov (1900-1928), engagé dans la vie politique transcaucasienne comme S.-R., puis comme militant du parti social-démocrate musulman Hümmet, et enfin comme membre de l'appareil du parti communiste bolchevique azerbaïdjanais, voit dans les élites bourgeoises qui mènent la campagne de pétitions des « forces vives de la Révolution » ${ }^{18}$. Le livre, que ce collaborateur scientifique du musée de la Révolution de Bakou a consacré aux Turcs d'Azerbaïdjan dans la révolution de 1905, écrit en 1925-1926, peu avant son arrestation et sa condamnation à mort en 1928, est resté inédit jusqu'en 2002. Il constitue une étude bien documentée, encore pleine de la passion que lui ont sans doute communiquée des acteurs de cette révolution qu'il a côtoyés, passion du progrès à répandre dans les masses locales, dont il décrit sans complaisance l'arriération.

La pétition des musulmans du Caucase a pour principal rédacteur Ali Mardan Bek Toptchibachy (Topčibašev), personnalité de premier plan du mouvement national des musulmans de Russie. Né en 1863 ou 1865 à Tiflis ${ }^{19}$, petit-fils d'un professeur à l'université des langues orientales de Saint-Pétersbourg, juriste et

16. Seidzade, Iz istorii azerbajdžanskoj buržuazii..., p. 54-77.

17. Ibid, entre autres, p. 39, 41, 54, 60, 65 .

18. Ahmedov, Azerbajdžanskie tjurki v revoljucii 1905 goda, p. 138.

19. La date de 1863 figure sur sa tombe à Saint-Cloud, celle de 1865 dans un curriculum vitae rédigé sans doute vers 1926 et conservé dans ses archives personnelles. 
avocat, il s'installe à Bakou en 1893. Il y devient, en 1897, le rédacteur en chef du journal en langue russe Kaspij [La Caspienne], défendant les intérêts des musulmans du Caucase et de tout l'Empire. À partir de 1905, il publie un journal en turc azéri, du nom de Hayat ou Gejat [La Vie]. Député à la Première Douma, il signe le manifeste de Vyborg et n'est donc plus éligible. Il est aussi l'un des dirigeants du parti Ittifak- i Muslimin [1'Union musulmane] créé à l'issue du congrès de NijniNovgorod (août 1905) et y joue un rôle de premier plan jusqu'en 1917. Occupant durant quelques mois les fonctions de président du Parlement et de ministre des Affaires étrangères de la république d'Azerbaïdjan proclamée en mai 1918, il part pour Istanbul puis pour Paris afin de prendre part à la Conférence de paix. Resté en exil après l'occupation bolchevique, il va s'investir dans les combats de l'émigration de l'ancien Empire russe, jusqu'à sa mort à Saint-Cloud en 1934.

La pétition des musulmans du Caucase a été présentée le 12 avril à Saint-Pétersbourg. Elle s'ouvre par un rappel de « l'union» des khanats musulmans à la Russie, il y a un peu plus de cent ans. Les musulmans, comme les autres nationalités du territoire, lit-on, ont accepté le gouvernement des Russes car il introduisait et développait les principes de la citoyenneté (graždanstvennost') et, par cela même, l'initiation du Caucase à la culture universelle. Mais, en cent ans, rien n'a été fait pour sortir la population de son état d'ignorance.

Elle se poursuit par la constatation suivante: «Les musulmans du Caucase forment l'élément le plus privé de droits », étant considérés par l'administration comme « un peuple presque de race inférieure » (narod čut' ne nizšej rasy), ils sont «dotés de droits dont on ne tient habituellement pas compte. Les musulmans du Caucase et, en général, les musulmans de Russie, sont - dans le sens plein du terme - les parias (pasynki) de l'Empire russe, et en tant que tels sont exclus de la famille des citoyens de Russie : ce sont des «allogènes » (inorodcy), considérés seulement comme des fidèles de la religion islamique - mahométans ou musulmans - et, dans le meilleur des cas, comme des sujets russes (russkopoddannye) ». Sujets soumis aux mêmes charges et obligations que le reste de la population de l'Empire, ils ne jouissent pas des mêmes droits. En tant qu' « élément étranger » (čuždyj element), les «allogènes » et les musulmans subissent des limitations de droit en tout.

Toptchibachy rappelle que les musulmans constituent le sixième de la population de l'Empire et occupent la première place après l'élément russe de souche (korennyj russkij element). Et c'est en raison d'un regard exclusivement confessionnel (veroispovednyj) à leur encontre qu'ils sont exclus de la masse de la population russe ${ }^{20}$.

Ce préambule émane d'un juriste qui emploie des mots précis, pesés et pertinents. Il est cependant sans concessions et n'hésite pas à parler de «parias », de « race inférieure». La même perception et les termes «parias de la société 
cultivée » (parii kul'turnago obščestva) se retrouvent dans la pétition des musulmans de la ville de Čistopol' dans le gouvernement de Kazan ${ }^{21}$.

Un point demande des éclaircissements: pourquoi se désigner comme « musulmans », réclamer le plein exercice des droits religieux et dénoncer un « regard exclusivement confessionnel » à l'égard des populations musulmanes ? Ces populations n'ont-elles pas elles-mêmes adopté cette attitude purement confessionnelle ? Dans sa rhétorique, Toptchibachy met d'abord en avant que c'est cette prise en compte de la seule appartenance religieuse qui empêche des sujets de l'Empire d'être des citoyens de plein droit. Or le fait d'être des sujets loyaux de l'Empire devrait automatiquement conférer des droits civiques. Cette argumentation prend tout son poids quand elle est replacée dans le contexte des discussions de l'époque sur la citoyenneté, notamment dans la revue Pravo créée et dirigée par Vladimir M. Gessen ${ }^{22}$.

Mais il faut aussi considérer que l'appellation «musulmans » a un contenu national. Dans ses Mémoires inédites, Toptchibachy commente cette étiquette de « musulmans » et explique que, pour les masses populaires, soumises à un pouvoir totalement étranger, il n'y avait de salut que dans la religion et que l'intelligentsia, consciente de l'impossibilité d'avancer des idées progressistes sur le terrain national, ne pouvait défendre ses intérêts nationaux, sociaux, économiques et politiques que sous le couvert de la religion ${ }^{23}$. Et il faut aussi avoir à l'esprit un point fondamental : l'intelligentsia musulmane du début du $\mathrm{XX}^{\mathrm{e}}$ siècle milite à la fois pour le progrès inspiré de l'Europe et du développement des sciences et techniques et pour la défense de l'islam. Un de ses illustres représentants, Ali Bey Huseinzade (1864-1941), membre de la délégation qui se rend à Saint-Pétersbourg en avril 1905 pour présenter la pétition des musulmans du Caucase et l'un des théoriciens précurseurs du panturquisme, popularise le slogan «turquifier, islamiser, européaniser » dans les colonnes de la presse azérie (1905-1907)24.

La pétition se poursuit par un long réquisitoire qui s'en prend à toutes les restrictions à l'encontre des musulmans, qu'elles soient inscrites dans la loi ou qu'elles résultent de dispositions gouvernementales ou de pratiques administratives, et à tous les aspects de la vie publique (administration, enseignement, justice...).

21. «Upolnomočennyh ot tatar-magometan g. Čistopol’, Kazanskoj gub., o graždanskih nuždah predsedatelju komiteta ministrov. Dokladnaja zapiska » [Note des plénipotentiaires des tatars-mahométans de la ville de Čistopol', gouvernement de Kazan, au président du Comité des ministres, sur les besoins des citoyens], Pravo, n 14, 10 avril 1905, col.1095.

22. Sur la citoyenneté définie comme un statut personnel impliquant des droits et des devoirs, égaux pour tous les membres d'un État nation, ses implications philosophiques et juridiques, l'idéal qu'elle représente et les limites de sa mise en œuvre dans le régime autocratique russe, voir l'excellent article d'Eric Lohr, «The Ideal Citizen and Real Subject in Late Imperial Russia », Kritika. Explorations in Russian and Eurasian History, 7 (2), 2006, p. 173-194.

23. Toptchibachy, «Musul'manskie s'ezdy v Rossii », iz serii «Vospominanij 1904-1907 gg » [Les congrès musulmans en Russie, dans la série « Mémoires 1904-1907 »], Archives personnelles de Toptchibachy, p. 3-4,

24. Tadeusz Swietochowski, Russian Azerbaidjan, 1905-1920: the Shaping of National Identity in a Muslim Community, Londres-New York-Melbourne : Cambridge University Press, 1985 , p. 33, 59 . 
Après ce réquisitoire, il est affirmé que les musulmans du Caucase veulent bénéficier, comme tous les autres peuples, de toutes les réformes qui vont être entreprises dans l'Empire. Ils demandent la suppression de toutes les restrictions à leur encontre et l'égalité des droits politiques, civiques et religieux avec les Russes, et en particulier les mêmes droits que les autres peuples en matière de participation de représentants librement élus à tous les organes consultatifs et législatifs qui vont être instaurés dans l'Empire ${ }^{25}$.

Parmi les revendications pour un libre exercice de l'islam, arrêtons-nous sur deux d'entre elles qui revêtent une importance particulière :

- le choix de nommer librement les membres du «clergé » musulman, du cheikh-ul-islam au mufti et aux mollah des paroisses ; la fin de l'administration des institutions spirituelles par le ministère de l'Intérieur et leur contrôle par les musulmans eux-mêmes, l'accès libre à ces fonctions pour des personnes formées dans l'Empire ou à l'étranger, à condition qu'elles connaissent le russe ${ }^{26}$. (Il s'agit en fait de l'accès aux fonctions religieuses musulmanes d'hommes formés dans les hauts lieux du chiisme, en Iran ou en Iraq, pour les chiites ; dans d'autres régions de l'Empire ottoman, pour les sunnites.)

- la restitution des biens vakuf, inaliénables selon le droit musulman, aux mosquées et aux lieux saints ${ }^{27}$. Cette revendication, commune à tous les musulmans de Russie, prend une signification particulière en Transcaucasie. En effet, les Arméniens avaient jusqu'à une époque récente conservé les biens de leur Église, particulièrement puissante et active. Mais la confiscation des biens du clergé arménien en 1903 a provoqué la mobilisation de toutes les couches de la population contre le pouvoir tsariste et explique en grande partie leur radicalisation sous l'égide du parti Dašnak $^{28}$. La restitution des biens confisqués aux églises et aux monastères arméniens et la restitution de leurs biens aux mosquées font partie des revendications de l'administration urbaine d'Erevan ${ }^{29}$. Le retour aux institutions religieuses de toutes confessions des biens leur ayant appartenu clôt la pétition du maire de Tiflis ${ }^{30}$. Or parmi les mesures prises par le gouvernement tsariste pour rétablir la paix au Caucase figure la restitution des biens au clergé de l'Église arménienne, décidée le $1^{\text {er }}$ août 1905, à la suite de quoi de larges pans de la société arménienne se désolidarisent du mouvement révolutionnaire ${ }^{31}$. Les musulmans, beaucoup moins massivement impliqués dans la révolution et pour lesquels la confiscation des biens des mosquées et lieux saints était plus ancienne, n'obtiendront pas satisfaction.

25. Pétition, col.1494.

26. Pétition, col.1495.

27. Ibid.

28. Anahide Ter Minassian, « Particularités de la révolution russe de 1905 en Transcaucasie », in Coquin, Gervais-Francelle, éds., 1905, la première révolution russe, p. 321.

29. «Peticija Erivanskago gorodskogo upravlenija... », col. 1407.

30. «Zapiska o mestnyh nuždah... », col. 1805.

31. Ter Minassian, « Particularités de la révolution russe... », p. 329. 


\section{Les enjeux territoriaux et nationaux}

Abordons maintenant les points de divergence les plus fondamentaux des pétitions présentées par les trois principaux peuples de Transcaucasie, qui ont des modes et des stades de développement national différents. Les seuls à définir clairement un territoire sont les Géorgiens, mais des enjeux territoriaux sous-tendent également certaines revendications des Arméniens ou des musulmans. Aucune pétition n'est séparatiste, mais la mise en place de nouvelles institutions soulève des questions territoriales.

Tant l'adresse des nobles de Tiflis que la pétition de la douma urbaine de Kutajsi définissent le territoire de la Géorgie, formé des gouvernements de Tiflis, Kutajsi, de l'oblast' de Batoumi et des districts de Soukhoumi et de Zakatala. Elles demandent l'instauration d'une Assemblée représentative de Géorgie, élue au suffrage universel et égalitaire. La pétition de la douma de Kutajsi appelle à une réforme politique radicale : l'autonomie nationale au sein d'un Empire russe décentralisé. Elle demande la réunion simultanée d'une Assemblée constituante panrusse et d'assemblées locales constituantes dans les marches (okrainy). Ainsi, la Géorgie autonome aura-t-elle un sejm à Tiflis et un statut organique élaboré par une Assemblée constituante locale.

La note du maire de Tiflis prône le développement de toutes les nationalités du Caucase (sans s'identifier à aucune d'entre elles) et demande l'instauration de circonscriptions électorales nationales pour leur représentation à l'Assemblée représentative panrusse, ainsi qu'un organe représentatif central pour tout le territoire (kraj) du Caucase. Rappelons que les populations arméniennes et musulmanes habitent alors des régions où elles sont très étroitement mêlées, que les Arméniens forment dans toute la Transcaucasie une importante partie de la population urbaine et qu'ils sont majoritaires à Tiflis. Vue de Saint-Pétersbourg, la Transcaucasie orientale est une région « arméno-tatare »32.

La pétition des Arméniens demande des zemstva par district et non par gouvernement, ce qui permettrait de pallier «l'absence de territoire national ${ }^{33}$. Les Arméniens sont en effet majoritaires dans trois des sept districts du gouvernement d'Erevan, dans deux des neuf districts du gouvernement de Tiflis, dans un des sept districts du gouvernement d'Elizavetpol' (Gandža).

La pétition des musulmans du Caucase ne précise rien sur l'organisation territoriale des futures institutions représentatives. Sa préoccupation majeure est d'être représentée en fonction de son importance numérique. Rappelons que ce n'était pas le cas dans la seule institution locale représentative introduite au Caucase avant 1905, la douma urbaine, où les «non chrétiens » ne pouvaient avoir qu'un

32. Sovet ministrov Rossijskoj Imperii, 1905-1906. Dokumenty i materialy [Conseil des ministres de l'Empire russe. Documents et notes], L. : Institut istorii SSSR, 1990, p. 124.

33. D. Ananoun, Rusahajéri hasarakakan zarkacume [Le développement des Arméniens de Russie], Venise, 1926, t. III, p. 145 et sq., cité par A. Ter Minassian, «Particularités de la révolution russe... », p. 325-326. 
cinquième, et dans les meilleurs cas la moitié, des élus, quel que soit leur nombre ${ }^{34}$. Cette disposition jouait en faveur des Russes, des Géorgiens, et surtout des Arméniens, au détriment des musulmans.

Pourtant, des enjeux territoriaux sous-tendent plusieurs des revendications des musulmans du Caucase. La paysannerie réclame l'arrêt de toute colonisation, demandant que les terres libres de l'État soient attribuées aux paysans locaux sans terre ou ayant peu de terre, ou encore temporairement dépendants, ainsi qu'à tous les agriculteurs. À l'inverse, la pétition des Arméniens plaide pour l'attribution de parcelles aux colons arméniens venus de Turquie et devenus sujets russes, dans les limites du kraj (territoire) du Caucase ${ }^{35}$. La pétition des musulmans prend la défense des éleveurs, auxquels doit être garantie la possibilité de poursuivre leur économie traditionnelle, avec pâturages d'hiver et d'été dans des zones différentes. Enfin, la pétition s'intéresse au statut de la terre au Daghestan et au Caucase du Nord et demande l'abrogation de la loi de 1900 qui a transformé les terres privées ou communautaires des montagnards en domaines de l'État ${ }^{36}$. La volonté de défendre la terre, qui doit rester entre les mains des autochtones, est donc clairement exprimée.

Cependant la question territoriale ne se pose pas de la même façon pour les trois peuples de Transcaucasie. Ce sont des représentants de territoires différents qui se regroupent sous la bannière de «musulmans du Caucase » lorsqu'ils présentent leur pétition à Saint-Pétersbourg en avril 1905, puis à Tiflis deux mois plus tard. Le territoire du Terek, peuplé de Tchétchènes, Ingouches, Kabardes et autres peuples montagnards, est représenté dans la première délégation, mais pas dans la seconde. Il en est de même pour le gouvernement d'Erevan, dans lequel les musulmans constituent $42 \%$ de la population. C'est l'inverse pour l'oblast' de Batoumi (Adjarie) et le district de Borčalo du gouvernement de Tiflis ${ }^{37}$. C'est donc une entité territoriale mouvante qui est liée aux « musulmans du Caucase ».

34. Sur la réforme des villes de 1870 , son application progressive à la Transcaucasie et les quotas de conseillers municipaux « non chrétiens » qui ont varié à plusieurs reprises et notamment après le règlement de 1892 et en 1900, voir : A.S. Mil’man, Političeskij stroj Azerbajdžana V XIX-načale XX vekov. Administrativnyj apparat $i$ sud. Formy i metody kolonial'nogo upravlenija [L'organisation politique de l'Azerbaïdjan au XIX ${ }^{\mathrm{e}}$ siècle et au début du XX $\mathrm{XX}^{\mathrm{e}}$. L'appareil administratif et la Justice. Les formes et les méthodes du gouvernement colonial], Bakou : Azernešr, 1966, p. 211-218; D. I. Ismail-Zade, Naselenie gorodov zakavkazskogo kraja $V X I X$ - načale $X X$ [La population de villes de Transcaucasie au XIXe siècle et au début du XXe], M. : Nauka, 1991, p. 193-196.

35. «Peticija Armjan », col. 1601.

36. Pétition, col. 1495-1496.

37. La composition de la délégation qui se rend à Saint-Pétersbourg le 12 avril 1905 est donnée dans une note manuscrite de Toptchibachy. Elle comporte des représentants des villes et gouvernements de Bakou et Elizavetpol', de la ville de Nakhitchevan et du gouvernement d'Erevan, de la ville de Vladikavkaz et du gouvernement du Terek et de la ville de Temir-han-šura et de l'oblast' du Daghestan (Archives personnelles de Toptchibachy). La délégation qui présente le texte de la pétition au vice-roi du Caucase, à Tiflis, le 10 juin, est composée de représentants des gouvernements de Bakou, d'Elizavetpol', du disctrict de Borčalo du gouvernement de Tiflis, des oblasti du Daghestan et de Batoumi («Musul'manskaja deputacija u namestnika Ego Imperatorskago Veličestva na Kavkaze grafa Il. Iv. Voroncova-Daškova » [La députation musulmane chez le viceroi de sa Majesté impériale au Caucase, le comte Il. Iv. Voroncov-Daškov], Kaspij, n ${ }^{\circ 16}$. Ce texte est intégralement reproduit par Ahmedov, Azerbajdžanskie tjurki..., p. 295-307. 
Comme on peut le constater, nous employons volontairement le terme « musulman ». Son remplacement systématique par « turc azéri » ou « azerbaïdjanais », comme cela se pratique souvent dans les textes des historiens azerbaïdjanais et dans ceux des chercheurs occidentaux, nous semble parfois inadéquat. Ici, en tout cas, on voit que par « musulmans du Caucase » il faut entendre ceux du Caucase du Nord et ceux de Transcaucasie. Ces derniers prendront effectivement l'ethnonyme de « Turcs » (tjurki), puis dans les années 1930 celui d' « Azerbaïdjanais ». De plus, les musulmans de Transcaucasie eux-mêmes ne sont pas tous « turcs », il y a parmi eux des Kurdes, des Lezghins, des Talyš ou des Tats (ces deux dernières ethnies parlant des langues du groupe iranien), et des Adjars de langue géorgienne.

Par ailleurs, l'identité nationale musulmane en construction en Transcaucasie orientale est encore « flexible ».Parmi les leaders de l'intelligentsia de ce début du XXe siècle, plusieurs ont commencé une carrière au Caucase et se sont aussi engagés dans la vie publique de l'Iran ou de l'Empire ottoman. Ainsi le journaliste Mehmed Emin Rasul Zade (1884-1954) qui appartient au groupe social-démocrate musulman Hümmet de Bakou, créé en 1904. Il gagne l'Iran en 1908, y édite un grand hebdomadaire de tendance démocrate et, de retour en Transcaucasie en 1913, devient l'un des leaders du parti nationaliste Musavat et de la première république d'Azerbaïdjan en 1918. Un autre représentant de ces élites caucasiennes, Ahmed Agaev ou Ağaoğlu (1869-1939), originaire de Šuša dans le Karabah, se considère comme « persan » et écrit sur l'Iran lors de ses études à Paris. De retour au Caucase, il entre en contact avec des intellectuels militants du nationalisme turc et défend les intérêts des musulmans du Caucase. Il est l'un des délégués de Bakou qui présentent la pétition au Comité des ministres, l'un des plus brillants journalistes engagés dans la cause nationale, l'un des créateurs du mouvement illégal Difai (Défense). Ce parti, aux assises populaires solides, organise l'autodéfense des musulmans sur le modèle des comités arméniens Dašnak, auxquels il s'oppose. Il est soumis à une sévère répression en 1908 et cesse alors ses activités ${ }^{38}$. Ağaoğlu gagne l'Empire ottoman où il participe au mouvement jeune-turc, puis kémaliste.

Plusieurs historiens de la construction nationale et du nationalisme turcs mettent l'accent sur leur spécificité. Holly Shissler voit dans la construction nationale azerbaïdjanaise ou turque non pas la réalisation d'une nation préexistante, mais un effort pour forger un projet commun qui sera efficace pour l'autopréservation d'une communauté dans des circonstances historiques particulières ${ }^{39}$. François Georgeon, commentant le passage d'Ağaoğlu de l'iranité à la turcité, fait aussi remarquer que « l'adoption du nationalisme à ses débuts a été, à l'intérieur de la référence essentielle à l'islam, un choix stratégique dicté par les circonstances de lieu, de temps, et le jeu des influences dominantes $»^{40}$.

38. I.S. Bagirova, Političeskie partii i organzacii Azerbajdžana v načale XX veka [Les partis et organisations politiques d'Azerbaïdjan au début du XXe siècle], Bakou : Elm, 1997, p. 179-188.

39. Holly Shisler, Between two Empires, Ahmed Agaoglu and the New Turkey, New York: Columbia University Press, 2002, p. 7-8.

40. François Georgeon, «Les débuts d'un intellectuel azerbaïdjanais : Ahmed Ağaoğlu en France, 1888-1894 », in Ch. Lemercier-Quelquejay, G. Veinstein, S.R. Wimbush, éds., Passé turco-tatar, présent soviétique : études offertes à Alexandre Benningsen, Louvain-Paris : Peeters, 1986, p. 387. 
Enfin, on ne saurait aborder les enjeux nationaux et territoriaux au Caucase sans évoquer les massacres interethniques auxquels a été donné le nom de «guerre arméno-tatare ». Ces massacres se produisent non seulement à Bakou, mais aussi dans les villes et campagnes des gouvernements d'Erevan et d'Elizavetpol' (Gandža) particulièrement dans les districts de Šuša et de Žangezur où les combats ne cessent qu'en juillet 1906. À Tiflis, il y est mis fin en novembre 1905, avec l'aide des sociaux-démocrates à qui le vice-roi a fait distribuer des armes. Les estimations du nombre de morts vont de 3100 à 10 000, avec de plus grandes pertes du côté tatar que du côté arménien pour certains historiens ${ }^{41}$, et l'inverse selon une vision plus largement diffusée ${ }^{42}$. Il n'est pas ici question de faire le point sur les responsabilités, les causes, le nombre des victimes, ni sur les versions divergentes de ces événements. Mais il semble utile de rappeler les interprétations données juste après les événements par les représentants des deux nationalités.

Tous les témoins s'accordent pour constater la passivité de la police, ou même la distribution d'armes aux musulmans pendant le premier pogrome de Bakou. Le discours révolutionnaire, par ailleurs protéiforme, fixe une interprétation selon laquelle ces massacres interethniques sont une opération de diversion lancée par le tsarisme contre le prolétariat multinational du Caucase. Cependant les délégués arméniens et musulmans, réunis à Tiflis au début de 1906 dans une commission de paix et qui rédigent un document consensuel comportant nombre de mesures approuvées par les uns et par les autres pour éviter de nouveaux heurts, ne s'accordent pas sur l'origine des massacres. Pour les délégués musulmans : «L'un des principaux motifs du développement des désordres arméno-tatars est l'activité des organisations secrètes arméniennes. Il est indispensable qu'elles cessent leur activité, autrement aucune paix solide n'est possible ». Pour les délégués arméniens : «L'un des principaux motifs de l'apparition et du développement des désordres arméno-tatars a été l'inaction et la complaisance des autorités locales. La formation d'organisations parmi les Arméniens est due à leurs pénibles conditions de vie... $\gg^{43}$. Ceux qui s'expriment dans cette réunion sont bien issus des élites nationales à l'origine des pétitions que nous avons étudiées, et ils militent tous pour l'arrêt des atrocités interethniques dont ils dénoncent les horreurs. Cependant, Toptchibachy, qui participe aux commissions de conciliation, analyse les causes de la guerre arméno-tatare et les expose dans une longue note d'octobre 1905 à l'intention du ministre des Finances, note qu'il n'a finalement pas envoyée. Il explique qu'à l'origine des massacres, il faut voir la politique russe, qui a toujours

41. T. Swietochowski, B.C. Collins, Historical Dictionary of Azerbaidjan, Lahan, MDLondres : The Scarecrow Press, 1999, p. 122-124.

42. C'est notamment la version donnée par la monumentale somme : L. Martov, P. Maslov et A. Potresov, dir., Obščestvennoe dviženie $v$ Rossii v načale $X X$ veka [Le mouvement social en Russie au début du Xxe siècle], Vol. IV, Saint-Pétersbourg: Tipografija to-va obščestvennaja

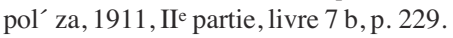

43. «Poželanija vyskazannyja armjanskimi i musul'manskimi delegatami v zasedanijah soveščanija o merah k prekraščeniju armjano-tatarskoj raspri »[ [Souhaits exprimés par les délégués arméniens et musulmans durant les séances de la conférence sur les mesures pour faire cesser les massacres arméno-tatars], document imprimé, Archives personnelles de Toptchibachy. 
privilégié les Arméniens aux dépens des musulmans, et le développement récent du mouvement national arménien ${ }^{44}$. Puis il s'en prend à l'acquisition par les Arméniens des terrains pétrolifères appartenant aux musulmans originaires de la région de Bakou, remarque que les comités arméniens ont armé la population là où le nombre des Arméniens était égal ou supérieur à celui des musulmans et que c'est dans ces endroits qu'ont eu lieu les heurts entre les deux communautés ${ }^{45}$. De plus, il s'insurge contre les mesures, envisagées par les industriels du pétrole, qui déposséderaient encore plus les musulmans des terrains pétrolifères ${ }^{46}$. Il n'est pas question de donner crédit à toutes ces assertions, mais simplement de prendre conscience du poids et de l'acuité des enjeux territoriaux antagonistes. La défense d'un territoire est donc bien présente dans les perceptions des musulmans du Caucase, même s'ils ne l'ont pas exprimée dans leur pétition d'avril 1905.

Par ailleurs, si dans le champ des opinions qui s'expriment au cours de cette campagne légale, il n'y a pas de référence à des bouleversements géopolitiques qui feraient sortir de l'Empire russe telle ou telle région du Caucase, de tels scénarios apparaissent cependant dans des textes de l'époque. La Fédération révolutionnaire arménienne publie à Genève l'analyse d'Aknouni, qui voit dans les massacres de 1905 le fruit d'une alliance provisoire entre les tyrans tsariste et panislamiste et dénonce les agissements des panislamistes dont le programme serait de profiter de la «situation créée en Russie par les victoires japonaises et les récentes secousses révolutionnaires » pour rétablir tôt ou tard la domination des sultans et des shahs sur la Transcaucasie ${ }^{47}$. Parallèlement, musulmans du Caucase et militants jeunesturcs en exil débattent dans des échanges épistolaires de différentes tactiques à adopter: panislamisme; alliance entre les Arméniens et les musulmans pour éliminer les Russes de la région; loyalisme (de façade au moins) à l'égard du gouvernement russe ${ }^{48}$.

Même s'il y a des échanges entre les élites engagées dans la vie politique et sociale de l'Empire russe et ces révolutionnaires, ils demeurent secrets et clandestins. En 1905, l'intelligentsia musulmane et les élites qui se rallient à ces idées ont foi dans les réformes et expriment de grands espoirs de changements et de progrès au sein de l'Empire russe. La campagne de pétitions au Caucase a constitué une occasion unique pour les intelligentsias nationales d'exprimer légalement leurs revendications. Il entre, certes, une part de tactique dans la rédaction de ces

44. «O bakinskih sobytijah. Dokladnaja zapiska. Gospodinu ministru Finansov» [Sur les événements de Bakou. Note à Monsieur le ministre des Finances], note dactylographiée datée d'octobre 1905 et portant la mention manuscrite «ne podana (non remise), archives personnelles de Toptchibachi,p. 1-10.

45. Ibid, p. 23.

46. Ibid, p. 29.

47. E. Aknouni, Les plaies du Caucase, Genève : La Fédération révolutionnaire arménienne, 1905, p. 338-340.

48. M. Şükrü Hanioğlu, Preparation for a Revolution : The Young Turks, 1902-1908, Oxford : Oxford Univesity Press, 2001,p. 159-161. 
pétitions qui doivent être acceptables pour le Comité des ministres. Celles-ci n'en demeurent pas moins des documents très intéressants. Les revendications exprimées en avril 1905 vont inspirer les interventions des députés musulmans du Caucase aux doumas d'État et les programmes de l'Union des musulmans. Mais, en définitive, aucune réforme ne va lever les restrictions qui pèsent sur les musulmans de Russie.

À partir de 1907-1908, des mesures répressives vont bloquer les évolutions souhaitées et freiner le développement des partis politiques nationaux en Transcaucasie. Mais, après la révolution de Février 1917, ce sont des projets déjà exposés en 1905 qui vont prendre corps, comme la création d'une assemblée (sejm) transcaucasienne et ce sont des litiges territoriaux qui vont faire éclater la première fédération transcaucasienne, litiges dont les élites nationales ont déjà en partie pris conscience en 1905. Enfin, des revendications exprimées en 1905, en particulier l'enseignement dans la langue maternelle et la participation massive des autochtones à la fonction publique, vont devenir les socles du programme national bolchevik mis en œuvre en Transcaucasie dans les années 1920.

La révolution de 1905 a donné une impulsion très importante au développement de la vie culturelle et des identités nationales des musulmans de Russie ainsi qu'à leurs mouvements de libération. Elle a aussi eu pour conséquence la participation aux institutions impériales, telle la Douma d'État, et à toutes sortes de commissions créées au niveau central ou local pour la préparation de réformes, d'un certain nombre de musulmans du Caucase, qui mettront l'expérience qu'ils y ont acquise au service de la première république d'Azerbaïdjan, dont ils deviendront les dirigeants.

\section{CNRS}

ybert.edith@neuf.fr 